\title{
Current Effect of Sedentary Screen Time on Child-Adolescent Health Outcomes
}

\section{Betsy D Gulledge*}

Director of BSN Program, Assistant Professor of Nursing, Jacksonville State University, 700 Pelham Road North, Jacksonville, AL 36265, USA

The advent of a more technological society has contributed to an increase in sedentary screen time activity (a spectrum of behaviors such as television watching, video gaming, texting, and computer activity). The proliferation of media available to children and adolescents warrants discussion as to effects of screen time exposure on health. The presence of screen time, beginning early in childhood, is a common reality for many children. As technology continues to become increasingly more complex, accessible, and a component of everyday life, so does the potential for adverse effects associated with too much screen time, too soon. Although moderated screen time may have some learning benefit, the issue of health outcomes is of particular concern to the health care provider. With meteoric advancements in technology, examining the effects of increased sedentary screen time becomes a priority.

It is known that sedentary activity has been associated with blood pressure elevations in children [1]. In children who participated in sedentary screen time activity, each hour increase in time engaged in sedentary activity was linked with an increase in systolic blood pressure $[2,3]$. Sedentary screen time activities have contributed to a decrease in physical activity in children. As a result of an increased time engaged in sedentary screen time, children participate in less physical activity contributing to the risk of developing adverse health outcomes, such as elevations in blood pressure. In addition, the amount of time children engage in sedentary screen time activities increases during middle school [4] contributing to earlier onset of elevated blood pressure levels; making early intervention a priority.

Elevated blood pressure levels are a significant concern from a global perspective. According to the World Health Organization [WHO] [5], twenty five percent of the global population (one billion people) is classified as hypertensive (a systolic or diastolic pressure equal to or greater than the 95th percentile at three separate office visits) [6]. The prevalence of hypertension is predicted to increase to over 1.56 billion people by the year 2025 [7]. More than 72 million American adults and 2-3 million American children have hypertension [8]. This is a significant problem in that, in the United States, the direct and indirect cost of hypertension is estimated to reach $\$ 1$ trillion by 2030 [9].

In addition, hypertension contributes to a variety of significant health issues including atherosclerosis, cerebrovascular disease, peripheral vascular disease, nephrosclerosis, and retinal damage [10]. In respect to the impact on children with elevated blood pressure, it is estimated that $2 \%-5 \%$ of children under the age of 18 meet criteria for a diagnosis of hypertension [11]. Children with hypertension are at a greater risk of having hypertension as an adult along with serious medical conditions such as stroke, myocardial infarction, vision impairment, kidney disease, and coronary artery disease as a result [1215]. Hypertension in children appears to develop at a much faster pace than in adults and with significant sequelae including left ventricular hypertrophy and increased carotid arterial initial medial thickness [16].

Because many children are not frequently assessed for elevated blood pressure readings, it becomes even more critical to address the impact of sedentary screen time activities and the status of health outcomes, such as blood pressure, in children. The solution is not an all-inclusive ban on screen time activities. The video gaming industry has made strides in offering more physically engaging games aimed at providing alternatives to traditional, sedentary video games. However, healthcare is struggling to maintain pace with the technological world. In an age of technology, it becomes the responsibility of the healthcare environment to anticipate and determine these effects on future generations and develop interventions focused on positive health outcomes for all.

\section{References}

1. Martinez-Gomez D, Tucker J, Heelan KA, Welk GJ, Eisenmann JC (2009) Associations between sedentary behavior and blood pressure in young children. Arch Pediatr Adolesc Med 163: 724-30.

2. Barclay L, Murata P (2005) School-age youth may need 1 hour of moderate exercise to vigorous physical activity daily to be healthy. J Pediatr 146: 719720, 732-737.

3. Sugiyama T, Xie D, Graham-Maar RC, Inoue K, Kobayashi Y, et al. (2007) Dietary and lifestyle factors associated with blood pressure among US adolescents. J Adolesc Health 40: 166-172.

4. Sisson SB, Church TS, Martin CK, Tudor-Locke C, Smith SR, et al. (2009) Profiles of sedentary behavior in children and adolescents: the US National Health and Nutrition Examination Survey, 2001-2006. Int J Pediatr Obes 4 353-359.

5. Whitworth JA (2003) 2003 World Health Organization (WHO)/Internationa Society of Hypertension (ISH) statement on management of hypertension. $J$ Hypertens 21: 1983-1992.

6. National Heart, Lung, and Blood Institute (NHLBI)/National Institutes of Health (2004) Blood pressure tables for children and adolescents. From the Fourth Report on the diagnosis, treatment, of high blood pressure in children and adolescents.

7. Kearney $\mathrm{P}$, Whelton $\mathrm{M}$, Reynolds $\mathrm{K}$, Muntner $\mathrm{P}$, Whelton $\mathrm{P}$, et al. (2005) Global burden of hypertension: analysis of worldwide date. Lancet 365: 217-223.

8. Kids Health from Nemours Foundation (2008) High blood pressure (Hypertension).

9. American Heart Association (2011) Forecasting the Future of Cardiovascular Disease in the United States.

10. National Heart, Lung, and Blood Institute (NHLBI) (2008) Disease Statistics In: 2010 fact book.

11. Sorof JM, Lai D, Turner J, Poffenbarger T, Portman RJ (2004) Overweight, ethnicity, and the prevalence of hypertension in school-aged children Pediatrics 113: 475-482.

12. Freedman DS, Khan LK, Dietz WH, Srinivasan SR, Berenson GS (2001) Relationship of childhood obesity to coronary heart disease risk factors in adulthood: the Bogalusa Heart Study. Pediatrics 108: 712-718.

*Corresponding author: Betsy D Gulledge, PhD, RN, Director of BSN Program, Assistant Professor of Nursing, Jacksonville State University, 700 Pelham Road North, Jacksonville, AL 36265, USA, E-mail: gulledge@jsu.edu

Received February 03, 2012; Accepted February 06, 2012; Published February 08, 2012

Citation: Gulledge BD (2012) Current Effect of Sedentary Screen Time on ChildAdolescent Health Outcomes. J Nurs Care 1:e102. doi:10.4172/2167-1168.1000e102

Copyright: (c) 2012 Gulledge BD. This is an open-access article distributed under the terms of the Creative Commons Attribution License, which permits unrestricted use, distribution, and reproduction in any medium, provided the original author and source are credited. 
Citation: Gulledge BD (2012) Current Effect of Sedentary Screen Time on Child-Adolescent Health Outcomes. J Nurs Care 1:e102. doi:10.4172/ 2167-1168.1000e102

Page 2 of 2

13. Haji SA, Ulusoy RE, Patel DA, Srinivasan SR, Chen W, et al. (2006) Predictors of left ventricular dilatation in young adults (from the Bogalusa Heart Study). Am J Cardiol 98: 1234-1237.

14. Orio F Jr, Palomba S, Cascella T, Savastano S, Lombardi G, et al. (2007) Cardiovascular complications of obesity in adolescents. J Endocrinol Invest 30: 70-80.
15. Schiel R, Beltschikow W, Radón S, Kramer G, Perenthaler T, et al. (2007) Increased carotid intima-media thickness and associations with cardiovascular risk factors in obese and overweight children and adolescents. Eur J Med Res 12: $503-508$.

16. Sorof JM, Turner J, Martin DS, Garcia K, Garami Z, et al. (2004) Cardiovascular risk factors and sequelae in hypertensive children identified by referral versus school-based screening. Hypertension 43: 214-218. 